\title{
Knowledge of Nursing Staff on Postoperative Pain: The Case of the Laquintinie Hospital in Douala, Cameroon
}

\section{Astride Houmkoua ${ }^{*}$, Olivier Pancha Mbouemboue1, Ousmana Oumarou², Henri Essome ${ }^{2,3}$, Emmanuel Balep ${ }^{1}$}

${ }^{1}$ Department of Biomedical Sciences, The University of Ngaoundere, Ngaoundere, Cameroon

${ }^{2}$ Laquintine Hospital of Douala, Douala, Cameroon

${ }^{3}$ Faculty of Medicine and Pharmaceutical Sciences of Douala, The University of Douala, Douala, Cameroon

Email: ^houmkouastre@gmail.com

How to cite this paper: Houmkoua, A., Mbouemboue, O.P., Oumarou, O., Essome, H. and Balep, E. (2021) Knowledge of Nursing Staff on Postoperative Pain: The Case of the Laquintinie Hospital in Douala, Cameroon. Journal of Biosciences and Medicines, 9, 120-131.

https://doi.org/10.4236/jbm.2021.95011

Received: February 14, 2021

Accepted: May 25, 2021

Published: May 28, 2021

Copyright $\odot 2021$ by author(s) and Scientific Research Publishing Inc. This work is licensed under the Creative Commons Attribution International License (CC BY 4.0).

http://creativecommons.org/licenses/by/4.0/

\begin{abstract}
Background and objective: Pain is a major concern in the surgical environment, but its management remains insufficient due to several factors related to the nursing staff, the organization of the structure or the patient himself. The objective of this study was to assess the knowledge of the nursing staff on postoperative pain at the Laquintinie Hospital in Douala. Methodology: This was a cross-sectional study carried out at the Laquintinie Hospital in Douala from September to December 2018. Participants were consecutively selected among members of nursing staff in charge of operated patients in the visceral surgery, trauma surgery, surgical reanimation, gynaecology and obstetrics services. Socio-professional data and data related to knowledge of postoperative pain were collected from this personnel using a pre-tested semi-structured questionnaire. Results: With regard to knowledge of postoperative pain, the proportion of correct answers to the knowledge questions was $61.4 \%$. This proportion varied significantly with the specific training received on pain and the specialization of the nursing staff $(\mathrm{p}<0.001)$. Conclusion: The results of the study reveal knowledge in this population that deserves to be improved with a view to better management of patients undergoing surgery.
\end{abstract}

\section{Keywords}

Nursing Staff, Postoperative Pain, Knowledge

\section{Introduction}

Post-surgical pain is one of the most important concerns in the surgical setting, 
as all surgical patients are exposed to it [1]. Its management requires a multidisciplinary approach [2]. Studies have shown that more than $80 \%$ of patients undergoing surgery had postoperative pain [3] [4] [5]. This pain is predictable, often acute [6] and constitutes a major physiological and psychological stress factor [7]. It also leads to an expansion of the postsurgical hospitalisation [8] and can become chronic [9]. The extent of complications related to postoperative pain depends on the quality of its management and justifies the attention paid by health care professionals improving quality of life of patients undergoing surgery. However, the management of this pain is regularly described as non-optimal [10] [11] [12] [13]. Several factors related to patients and the organisation of surgical services have been cited to justify this inadequacy in the management of postoperative pain. Among them, the knowledge and perception of postoperative pain by the nursing staff appear to be recurrent [12]-[19].

The aim of this study was to assess the knowledge of the nursing staff about postoperative pain in the surgical, gynaecological and surgical reanimation departments of the Laquintinie Hospital.

\section{Materials and Methods}

\subsection{Study Design and Population}

This was a cross-sectional study conducted at the Laquintinie Hospital in Douala from September to December 2018. The study population was nursing staff in charge of operated patients. Participants were consecutively selected among members of visceral surgery, trauma surgery, surgical reanimation, gynaecology and obstetrics departments who provided a written consent.

\subsection{Study Variables and Data Collection}

Data were collected using a pre-test semi-structured questionnaire designed by the authors (see Appendix 1). This questionnaire was adapted from international Guidelines on Management of Postoperative Pain [20] [21] [22] [23]. It was made up of 18 questions grouped under two items. The first item concerned socio-professional characteristics of participants and was constituted of 7 questions and the second concerned their knowledge on postoperative pain and was constituted of 11 questions. In this item, 21 right answers were proposed to the participants.

The participants' level of knowledge was considered sufficient for those who provided at list $80 \%$ of the right answers (16 right answers for this item), as described by Mc Caffery and Robinson as the minimum level of knowledge about postoperative pain [24]. It was given to each participant to fulfill the questionnaire alone without the investigators' help. The questionnaire was pre-tested with similar nurses' staff in a hospital in Douala (Cameroon).

\subsection{Data Analysis}

The data were analyzed using SPHINX PLUS ${ }^{2}$ software version 5.1.0.7 Lexica 
Edition. This analysis consisted of the calculation of averages and proportions. The Chi-square test was used to compare the level of knowledge between the different groups. The results were considered significantly related for $\mathrm{p}$ values below 0.05 .

\subsection{Ethical Considerations}

This study was authorized by the Ethics Committee of the University of Ngaoundéré (Ref.: 2018/120/UN/DFS/CD-SBM) and the Ethics Committee of the Laquintinie Hospital of Douala (Ref.: 3972/AR/MINSANTE/DHL/CM). An informed consent form was signed by each participant.

\section{Results}

\subsection{Socio-Professional Characteristics of the Participants}

A total of 51 health care personnel ( $16 \%$ men and $84 \%$ women) were included in this study. Their average age and on-the-job time in the profession was $36.10 \pm$ 8.74 years and $10.98 \pm 8.70$ years respectively. The majority of these participants were staff who did not specialise in the care of patients undergoing surgery (58.8\%) and had been trained in postoperative management (64.7\%). The socio-professional characteristics described are presented in Table 1.

Table 1. Distribution of nursing personnel according to socio-professional characteristics.

\begin{tabular}{lcc}
\hline \multicolumn{1}{c}{ Variables } & $\mathrm{N}=51$ & $\%$ \\
\hline Gender & 43 & 84.3 \\
Female & 8 & 15.7 \\
Male & & \\
Age, (average: $36.10 \pm 8.74$ years) & 15 & 29.4 \\
Less than 30 & 11 & 21.6 \\
$\quad$ From 30 to 35 & 14 & 27.5 \\
$\quad$ From 35 to 41 & 5 & 9.8 \\
$\quad$ From 41 to 47 & 3 & 5.9 \\
From 47 to 53 & 3 & 5.9 \\
53 and over & & \\
Specialty & 21 & 41.2 \\
$\quad$ Specialist Nurse & 30 & 58.8 \\
$\quad$ Non-specialist Nurse & & \\
Seniority in the profession (average: $10.98 \pm 8.70$ years) & 10 & 27.5 \\
Less than 6 & 14 & 35.3 \\
6 to 11 & & 19.6 \\
11 to 17 & & \\
17 and over & & \\
\hline
\end{tabular}




\section{Continued}

Seniority in the service (average: $6.92 \pm 6.13$ years)

$\begin{array}{lcc}\text { Less than } 6 & 27 & 52.9 \\ \text { From } 6 \text { to } 11 & 12 & 23.5 \\ \text { From } 11 \text { to } 17 & 7 & 13.7 \\ 17 \text { and over } & 5 & 9.8 \\ \text { ining received on postoperative pain } & 33 & 64.7 \\ \text { Yes } & 18 & 35.3 \\ \text { No } & & \\ \text { Initial training } & 20 & 60.6 \\ \text { Continuing education } & 13 & 39.4\end{array}$

\subsection{Knowledge of Postoperative Pain by Participants}

The level of knowledge of postoperative pain among participants in this study was estimated at $61.4 \%$. The most well-known aspects of postoperative pain were: the influence of the type of surgery (82.4\%), the possibility of preventing postoperative pain (94.1\%) and the administration of intravenous analgesics as first-line treatment in the immediate postoperative period (80.4\%). The less-known items were the haemodynamic effect as one of the effects of postoperative pain on the rest of body (11.9\%), the existence of a preoperative pain as a factor influencing postoperative pain (7.8\%) and hetero-rating scale as a pain tools assessment (13.7\%). The overall knowledge of the nursing staff about postoperative pain in this study is presented in Table 2.

\subsection{Socio-Professional Characteristics and Level of Knowledge of the Nursing Staff about Postoperative Pain}

With regard to the statistical link between socio-professional characteristics and knowledge, only the specific training received on postoperative pain and staff specialisation had a significant relationship with the level of knowledge ( $\mathrm{p}<$ 0.001). No link was found between knowledge and the type of training received $(\mathrm{p}=0.999)$, seniority in the service $(\mathrm{p}=0.784)$ and profession $(\mathrm{p}=0.934)$. The relationship between socio-professional characteristics and level of knowledge is presented in Table 3.

\section{Discussion}

\subsection{Socio-Professional Characteristics of the Participants}

This study investigated knowledge of the nursing staff on postoperative pain at the Laquintinie Hospital (Douala, Cameroon). A total of 51 nursing staff members were included in this study: 43 women (84\%) and 8 men (15.7\%). The majority of women among participants has also been reported by several authors in similar studies [25] [26]. This finding supports the general observation that there 
Table 2. Participants' knowledge on postoperative pain.

\begin{tabular}{|c|c|c|}
\hline \multirow{2}{*}{ Aspects of knowledge about postoperative pain } & \multicolumn{2}{|c|}{ Correct answers } \\
\hline & $\mathrm{N}^{*}$ & $\%$ \\
\hline \multicolumn{3}{|l|}{ Type and impact of postoperative pain } \\
\hline Postoperative pain is nociceptive pain & 29 & 56.9 \\
\hline Postoperative pain can have an impact on the body & 42 & 82.4 \\
\hline \multicolumn{3}{|l|}{ The effects of postoperative pain: } \\
\hline Psychological & 28 & 66.7 \\
\hline Haemodynamic & 5 & 11.9 \\
\hline Digestive & 22 & 52.4 \\
\hline Cardiorespiratory & 31 & 73.8 \\
\hline \multicolumn{3}{|l|}{ Factors influencing postoperative pain } \\
\hline Age & 11 & 21.6 \\
\hline Gender & 14 & 27.5 \\
\hline Anaesthesia technique & 40 & 78.4 \\
\hline Type of surgery & 41 & 80.4 \\
\hline Anxiety & 28 & 54.9 \\
\hline Existence of preoperative pain & 4 & 7.8 \\
\hline \multicolumn{3}{|l|}{ Prevention of postoperative pain } \\
\hline Is it possible to prevent postoperative pain? & 48 & 94.1 \\
\hline Prevention of postoperative pain begins in the preoperative period & 38 & 79.2 \\
\hline \multicolumn{3}{|l|}{ Evaluation of postoperative pain and its tools } \\
\hline Is the hetero-rating scale a tool? & 7 & 13.7 \\
\hline Is verbal rating scale a tool? & 17 & 33.3 \\
\hline Is numeric rating scale a tool? & 23 & 45.1 \\
\hline Is visual analog scale a tool? & 14 & 27.5 \\
\hline \multicolumn{3}{|l|}{ Postoperative pain management } \\
\hline $\begin{array}{l}\text { Patient's opinions and the level of understanding should be } \\
\text { considered in the postoperative pain management }\end{array}$ & 29 & 56.9 \\
\hline Postoperative pain management is very important & 39 & 76.5 \\
\hline $\begin{array}{l}\text { The recommended route of administration pain medication is } \\
\text { intravenous }\end{array}$ & 44 & 86.3 \\
\hline It is right for the patient to expect complete pain relief & 41 & 86.4 \\
\hline
\end{tabular}

are more women than men in care settings [27]. The average age of the participants $(36.10 \pm 8.74$ years) was close to those reported by Nahid et al. in Iran (33.5 years) and Houzou et al. in Togo (35 years), respectively [28] [29]. With regard to their professional characteristics, only $41.2 \%$ of the study participants were specialised in the management of patients undergoing surgery. This includes 
Table 3. Socio-professional characteristics and level of knowledge of the nursing staff about postoperative pain.

\begin{tabular}{|c|c|c|c|}
\hline \multirow{2}{*}{ Socio-professional characteristics } & \multicolumn{2}{|c|}{ Level of knowledge } & \multirow{2}{*}{$\mathrm{P}$} \\
\hline & $\mathrm{N}$ & $\%$ & \\
\hline \multicolumn{4}{|c|}{ Specific training received on the postoperative pain } \\
\hline Yes & 489 & 64.4 & \multirow[b]{2}{*}{$<0.001$} \\
\hline No & 162 & 39.3 & \\
\hline \multicolumn{4}{|c|}{ Type of training received on the postoperative pain } \\
\hline Initial training & 317 & 75.8 & \multirow{2}{*}{0.999} \\
\hline Continuing education & 219 & 58.6 & \\
\hline \multicolumn{4}{|l|}{ Staff specialisation } \\
\hline Specialised personnel & 317 & 68.6 & \multirow[b]{2}{*}{$<0.001$} \\
\hline Non specialised personnel & 267 & 40.5 & \\
\hline \multicolumn{4}{|l|}{ Seniority in the service (in years) } \\
\hline Less than 7 & 337 & 47.9 & \multirow{3}{*}{0.784} \\
\hline 7 to 14 & 174 & 65.9 & \\
\hline Greater than 14 & 84 & 54.5 & \\
\hline \multicolumn{4}{|l|}{ Seniority in the profession (in years) } \\
\hline Less than 11 & 350 & 54.9 & \multirow{3}{*}{0.934} \\
\hline 11 to 20 years & 202 & 61.2 & \\
\hline Greater than 20 & 71 & 46.1 & \\
\hline
\end{tabular}

nurses' anaesthetists and surgical nurses, who are effectively trained in the management of postoperative pain during their professional training. Priority should be given to them during recruitments for services where patient undergo surgery. However, nurses who are not specialised in management of patient undergoing surgery need continuous education focused on specific issues like postoperative pain management in order to be able to work effectively with patient undergoing surgery. Indeed, continuous training is known to allow professionals to upgrade their knowledge and skills [30]. In this study, 35.3\% of the participants have never been trained on postoperative pain management during their professional training or continuous education. Beyond initial or continuous education, seniority of nurses in services where patients undergo surgery may help them improving their knowledge and skills in managing operated patients. The study results revealed that $52.9 \%$ of the participants had spent less than 7 years in selected departments.

\subsection{Participants' Knowledge of Postoperative Pain}

The influence of the surgery and anaesthesia methods on postoperative pain was known by the majority of study participants (78.4\%). In addition, $94.1 \%$ of the participants knew that it is possible to prevent postoperative pain and $79.2 \%$ of 
them knew that this prevention starts in the preoperative period. These proportions are close to those reported by Lokossou et al. [31], and corroborate international recommendations according to which nursing staff should carry out preoperative assessment in order to identify patients at risk and adjust their management [20] [21]. It is now known that discussing about pain management with patients in the preoperative period contributes to improve postoperative pain management outcomes [32].

Difficulties faced by caregivers in assessing patients' pain have led experts to build and promote various pain assessment tools [20]. For many reasons, some of them are more popular than others. Numerical and verbal rating scales are known to be easy to use [33] [34] [35], while visual analog scale presents higher reliability and validity that make it commonly used in medical practice and research [36]. The results of this study indicate that only $27.5 \%$ of the participants knew that the visual analog scale is a tool for pain assessment. This lack of knowledge of pain assessment tools by study participants may reflect lack of pain management in our context. Concerning the recommended route of administration pain medication, most of the participants $(86.3 \%)$ were aware that the intravenous route is the one recommended for pain medication in postoperative period. These results show that the knowledge of study participants about the route of administration of the analgesics are in line with international recommendations according to which the intravenous route is the best for administrating first doses of analgesics in the postoperative period [21] [22] [23].

As suggested by McCaffery and Robinson, the minimum level of knowledge about postoperative pain was set at $80 \%$ in this study [24]. The level of knowledge about postoperative pain found in the study population was estimated at $61.4 \%$. Therefore, the observed level of knowledge was considered insufficient in the study population. The nature of the questionnaire used to assess the level of participants' knowledge about postoperative pain in this study may have played a role in the insufficient level of knowledge observed [37]. Previous studies have revealed lower levels of knowledge about postoperative pain in others countries. Nahid et al. and Zanolin et al. have reported $45.7 \%$ and $47.6 \%$ levels of nursing knowledge on postoperative pain in Jordan and Italy respectively [28] [37]. The differences observed between our results and those of these studies may be due to differences in knowledge assessment tools used.

Managing postoperative pain requires a minimum qualification. This qualification is acquired during the initial and continuous training of nursing personnel in which assessment tools, prevention and management are well studied. Qualified personnel are intended to have higher quality of knowledge and practice than those who are not. In this study, participants who received specific initial or continuous training on postoperative pain presented higher level of knowledge than those who did not $(p=0.001)$. Although, several elements could explain this finding, particularly the quality of the training received, the importance that the nursing staff attaches to continuing education and the period elapsed between the continuing education received and the evaluation during 
our study. Otherwise, there was no association between type of training (initial or continuous) and the participants level of knowledge about postoperative pain. A similar observation to this finding has been done by Gordon et al. [38].

No association was found in this study between level of participants' knowledge and their seniority in their different departments in one hand, and their seniority in the nursing profession in the other hand. Concerning lack of association between participants' knowledge and seniority in their different services, the results of the present study are closed to those reported by Al-Shaer et al. [39]. The lack of association concerning participant's knowledge and seniority in services found in this study suppose a problem of Learning by doing principles in our context. According to Gil-Lacruz et al. Learning by doing training is an interesting potential for improvement of quality of health care and skills of health person [40]. Also, as in previous studies, seniority in profession had not shown any association with participants' level of knowledge [41] [42].

\section{Limitations}

The main limitation of the study is the small sample size of the study population. However, all the participants were in charge of operated patients and, their answers may reflect the knowledge about postoperative pain management of nursing staff in the Laquintinie Hospital at the moment of this study.

\section{Conclusion}

The study shows that the level of knowledge of the nursing staff about postoperative pain is insufficient at the Laquintinie Hospital in Douala and that staff training is only of real interest when it provides specific knowledge about postoperative pain.

\section{Conflicts of Interest}

The authors declare no conflicts of interest regarding the publication of this paper.

\section{References}

[1] Ger, L., Chang, C., Ho, S., Lee, M., Chiang, H., Chao, C., Lai, K., Huang, J. and Wangs, S. (2004) Effects of a Continuing Education Program on Nurses' Practices of Cancer Pain Assessment and Their Acceptance of Patients' Pain Reports. Journal of Pain and Symptom Management, 27, 61-71. https://doi.org/10.1016/j.jpainsymman.2003.05.006

[2] Kehlet, H. and Dahl, J.B. (1993) Postoperative Pain. World Journal of Surgery, 17, 215-219. https://doi.org/10.1007/BF01658929

[3] Apfelbaum, J.L., Chen, C., Mehta, S.S. and Gan, T.J. (2003) Postoperative Pain Experience: Results from a National Survey Suggest Postoperative Pain Continues to Be Undermanaged. Anesthesia \& Analgesia, 97, 534-540. https://doi.org/10.1213/01.ANE.0000068822.10113.9E

[4] Li, L., Liu, X.Q. and Herr, K. (2007) Postoperative Pain Intensity Assessment: A 
Comparison of Four Scales in Chinese Adults Pain Medicine. Pain Medicine, 8, 224-233. https://doi.org/10.1111/j.1526-4637.2007.00296.x

[5] Atangana, R., Bahebeck, J., Ngowe Ngowe, M., Eyenga, Hentchoya, R., Manyacka, P., Ze Mikande, J., Binam, F. and Abolo, M. (2006) Prise en charge de la douleur post-opératoire immédiate en salle de soins post interventionnels. Clinics in Mother and Child Health, 3, 473-476.

[6] Bonica, J.J. (1990) Postoperative Pain. In: Bonica, J.J., Ed., The Management of Pain, Lea \& Febiger, Philadelphia, 461-480.

[7] Hallenberg, B., Bergbom-Engberg, I. and Haljamäe, H. (1990) Patients' Experiences of Postoperative Respirator Treatment-Influence of Anaesthetic and Pain Treatment Regimens. Acta Anaesthesiologica Scandinavica, 34, 557-562. https://doi.org/10.1111/j.1399-6576.1990.tb03145.x

[8] Schug, S.A. and Chong, C. (2009) Pain Management after Ambulatory Surgery. Current Opinion in Anesthesiology, 22, 738-774. https://doi.org/10.1097/ACO.0b013e32833020f4

[9] Kehlet, H., Jensen, T. and Woolf, C. (2006) Persistent Postoperative Pain: Risk Factors and Prevention. The Lancet, 367, 1618-1625. https://doi.org/10.1016/S0140-6736(06)68700-X

[10] Breivik, H. and Stubhaug (2008) Management of Acute Postoperative Pain: Still a Long Way to Go! Pain, 137, 233-234. https://doi.org/10.1016/j.pain.2008.04.014

[11] Wang, X.S., Tang, J.Y. and Zhao, M. (2003) Pediatric Cancer Pain Management Practices and Attitudes in China. Journal of Pain and Symptom Management, 26, 748-759. https://doi.org/10.1016/S0885-3924(03)00242-2

[12] Maysoon, S., Abdalrahim, C., Sawsan, A., Majali, Stomberg, M.W. and Bergbom, I. (2011) The Effect of Postoperative Pain Management Program on Improving Nurses Knowledge and Attitudes toward Pain. Nurse Education in Practice, 11, 250-255. https://doi.org/10.1016/j.nepr.2010.11.016

[13] Yates, P.M., Edwards, H.E. and Nash, R.E. (2002) Barriers to Effective Cancer Pain Management: A Survey of Hospitalized Cancer Patients in Australia. Journal of Pain and Symptom Management, 23, 393-405. https://doi.org/10.1016/S0885-3924(02)00387-1

[14] Chauvin, M. (1999) Prise en charge post opératoire: La douleur après l'intervention chirurgicale: Prise en charge post opératoire. La Presse Médicale, 28, 203-211.

[15] Manias, E., Botti, M. and Bucknall, T. (2002) Observation of Pain Assessment and Management-The Complexities of Clinical Practice. Journal of Clinical Nursing, 11, 724-733. https://doi.org/10.1046/j.1365-2702.2002.00691.x

[16] Botti, M., Bucknall, T. and Manias, E. (2004) The Problem of Postoperative Pain: Issues for Future Research. International Journal of Nursing Practice, 10, 257-263. https://doi.org/10.1111/j.1440-172x.2004.00487.x

[17] Ardery, G., Herr, K., Hannon, B. and Titler, M. (2003) Lack of Opioid Administration in Older Hip Fracture Patients. Geriatric Nursing, 24, 353-360. https://doi.org/10.1016/j.gerinurse.2003.09.006

[18] Ouro Bang'Na Maman, A.-F., Agbétra, N., Moumouni, I., Tomta, K. and Chobli, M. (2006) Prise en charge de la douleur postopératoire au Togo: Connaissance et attitude des prescripteurs. Canadian Journal of Anesthesia, 53, 529-531. https://doi.org/10.1007/BF03022633

[19] Christne, M., Ufashingabire, E.N., Kato, J. and Njunwa, P.B. (2016) Knowledge and Attitudes of Nurses Regarding Pain in the Intensive Care Unit Patents in Rwanda. 
Rwanda Journal Series F: Medicine and Health Sciences, 3, 21-25. https://doi.org/10.4314/rj.v3i1.4F

[20] Langlade, A., Bellanger, F., Cornet, C., Monrigal, M.C., Ballandyne, S. and Bonner, F. (2002) Démarche assurance-qualité pour la prise en charge des douleurs postopératoires: Proposition d'un outil de réalisation d'enquêtes. Annales Françaises d Anesthésie et de Réanimation, 21, 276-294. https://doi.org/10.1016/S0750-7658(02)00605-6

[21] Chou, R., et al. (2016) Guidelines on the Management of Postoperative Pain, Management of Postoperative Pain: A Clinical Practice Guideline from the American Pain Society, the American Society of Regional Anesthesia and Pain Medicine, and the American Society of Anesthesiologists. The Journal of Pain, 17, 131-157. https://doi.org/10.1016/j.jpain.2015.12.008

[22] Aubrun, F., Nouette, G.K., Fletcher, D., Belbachir, A., Beloeil, H., Carles, M., Cuvillon, P., Dadure, C., Lebuffe, G., Marret, E., Martinez, V., Olivier, M., Sabourdin, N. and Zetlaoui (2016) Réactualisation et recommandation sur la douleur post opératoire. Société Française d'Anesthésie et de Réanimation. Anesth Reanim. https://doi.org/10.1016/j.anrea.2016.09.006

[23] Association des infirmières et infirmiers autorisés de l'Ontario (2013) Lignes directrices sur les pratiques cliniques exemplaires Évaluation et prise en charge de la douleur. 3e edition.

[24] McCaffery, M. and Robinson, E.S. (2002) Your Patient Is in Pain-Here's How You Respond. Nursing, 32, 36-45. https://doi.org/10.1097/00152193-200210000-00042

[25] Young, J., Horton, F. and Davidhizar (2006) Nursing Attitudes and Beliefs in Pain Assessment and Management. Journal of Advanced Nursing, 53, 412-421. https://doi.org/10.1111/j.1365-2648.2006.03735.x

[26] Hong, S.J. and Lee, E. (2014) Effect of Evidence-Based Postoperative Pain Guidelines via Web for Patients Undergoing Abdominal Surgery in South Korea. Asian Nursing Research, 8, 135-142. https://doi.org/10.1016/j.anr.2014.05.005

[27] Rajacich, D., Kane, D., Williston, C. and Cameron, S. (2013) If They Do Call You a Nurse, It Is Always a "Male Nurse": Experiences of Men in the Nursing Profession. Nursing Forum, 48, 71-80. https://doi.org/10.1111/nuf.12008

[28] Rejeh, N., Ahmadi, F., Mohammadi, E., Kazemnejad, A. and Anoosheh, M. (2009) Nurses' Experiences and Perceptions of Influencing Barriers to Postoperative Pain Management. Scandinavian Journal of Caring Sciences, 23, 274-281. https://doi.org/10.1111/j.1471-6712.2008.00619.x

[29] Prénam, H., Kodjo, K., Komi, A., Esso djêlina, A., Dake, K.S., Arafat, D., Salifou, I., Kantame, S., Eyram, F., et al. (2018) Prise En Charge Infirmière De La Douleur Chez L'adulte Au CHU-Kara (Togo). European Scientific Journal, 14, 192. https://doi.org/10.19044/esj.2018.v14n6p192

[30] Pades, A. and Homar, C. (2006) El estrés de los estudiantes en las prácticas clínicas de enfermería. Revista ROL de Enfermería, 29, 577-582.

[31] Lokossou, T.A.F., Ouro-Bang'na, M., Méhinto, D.K., Mensah, E., Assouto, P. and Chobi, M. (2007) Attitude et connaissance des praticiens face à la douleur postopératoire dans les centres hospitaliers départementaux du Bénin. Douleur \& Analgésie, 2, 91-99. https://doi.org/10.1007/s11724-007-0037-4

[32] Niemi-Murola, L., Pöyhiä, R., Onkinen, K., Rhen, B., Mäkelä, A. and Niemi, T.T. (2007) Patient Satisfaction with Postoperative Pain Management Effect of Preoperative Factors. Pain Management Nursing, 8, 122-129. 
https://doi.org/10.1016/j.pmn.2007.05.003

[33] Jensen, M.P., Miller, L. and Fisher, L.D. (1998) Assessment of Pain during Medical Procedures: A Comparison of Three Scales. The Clinical Journal of Pain, 14, 343-349. https://doi.org/10.1097/00002508-199812000-00012

[34] Paice, J.A. and Cohen, F.L. (1997) Validity of a Verbally Administered Numeric Rating Scale to Measure Cancer Pain Intensity. Cancer Nursing, 20, 88-93. https://doi.org/10.1097/00002820-199704000-00002

[35] Ohnhaus, E.E. and Adler, R. (1975) Methodological Problems in the Measurement of Pain: A Comparison between the Verbal Rating Scale and the Visual Analogue Scale. Pain, 1, 379-384. https://doi.org/10.1016/0304-3959(75)90075-5

[36] Briggs, M. and Closs, J.S. (1999) A Descriptive Study of the Use of Visual Analogue Scales and Verbal Rating Scales for the Assessment of Postoperative Pain in Orthopedic Patients. Journal of Pain and Symptom Management, 18, 438-446. https://doi.org/10.1016/S0885-3924(99)00092-5

[37] Elisabetta, Z.M., Visentin, M., Trentin, L., Saiani, L., Brugnolli, A. and Mario, G.A. (2007) Questionnaire to Evaluate the Knowledge and Attitudes of Health Care Providers on Pain. Journal of Pain and Symptom Management, 33, 727-736.

https://doi.org/10.1016/j.jpainsymman.2006.09.032

[38] Gordon, D.B., Pellino, T.A., Higgins, G.A., Pasero, C. and Murphy-Ende, K. (2008) Nurses' Opinions on Appropriate Administration of PRN Range Opioid Analgesic Orders for Acute Pain. Pain Management Nursing, 9, 131-140.

https://doi.org/10.1016/j.pmn.2008.03.003

[39] Al-Shaer, D., Hill, P.D. and Anderson, M.A. (2011) Nurses' Knowledge and Attitudes Regarding Pain Assessment and Intervention. Medical-Surgical Nursing, 20, 7-11.

[40] Gil-Lacruz, M., Gracia-Pérez, M.L. and Gil-Lacruz, A.I. (2019) Learning by Doing and Training Satisfaction: An Evaluation by Health Care Professionals. International Journal of Environmental Research and Public Health, 16, 1397. https://doi.org/10.3390/ijerph16081397

[41] Lui, L.Y., So, W.K. and Fong, D.Y. (2008) Knowledge and Attitudes Regarding Pain Management among Nurses in Hong Kong. Medical Journal of Clinical Nursing, 17, 2014-2021. https://doi.org/10.1111/j.1365-2702.2007.02183.x

[42] Wilson, B. (2007) Nurses' Knowledge of Pain. Journal of Clinical Nursing, 16, 1012-1020. https://doi.org/10.1111/j.1365-2702.2007.01692.x 


\section{Appendix 1}

\section{Semi-structured questionnaire on knowledge of nursing staff on postopera- tive Pain at the Laquintinie Hospital in Douala (Cameroon) \\ 1) Socio-professional characteristics of the Nursing Staff Choose one answer}

\begin{tabular}{lll}
\hline $\mathrm{N}^{\circ}$ & \multicolumn{1}{c}{ Identification } \\
\hline 1 & Age (in years) & \\
2 & Gender & $\square$ Female $\square$ Male \\
3 & Category of nursing staff & $\square$ Specialist Nurse $\square$ Non-specialist Nurse \\
4 & Seniority in service (in years) & \\
5 & Specific training received on post-operative pain & $\square$ Yes $\square$ No \\
6 & If yes, what type of training was received? & $\square$ Initial training $\square$ Continuing education \\
7 & Length of service (in years) & \\
\hline
\end{tabular}

\section{2) Knowledge of postoperative pain by Nursing Staff}

\section{Choose the correct(s) answer(s)}

8 Is postoperative pain a nociceptive type of pain? $\square$ Yes $\square$ No $\square$ Don't know

9 Do you think that post-operative pain can have an impact on the body?

$\square$ Yes $\square$ No $\square$ Don't know

10 If so, which ones?

$\square$ Cardiorespiratory $\square$ Hemostasis $\square$ Digestive $\square$ Psychological

11 What factors influence postoperative pain?

$\square$ Gender $\square$ Anaesthetic technique

12 It is possible to prevent postoperative pain? $\square$ Type of surgery $\square$ Anxiety $\square$ Age $\square$ Presence of pre-operative pain When does the prevention of postoperative pain begin?

$\square$ Yes $\square$ No $\square$ Don't know

$\square$ Pre-operatively $\square$ Per-operatively

$\square$ Post-operatively

$\square$ By hetero-rating scale

$\square$ By verbal rating scale

14 By what means do you carry out the evaluation of $\square$ By numeric rating scale

the postoperative pain?

$\square$ By visual analogue scales

$\square$ By analgesic consumption

$\square$ By patient complaint

$\square$ No assessment

Is the patients' opinions and the level of

15 understanding should be considered in the

$\square$ Yes $\square$ No $\square$ Don’t know postoperative pain management?

Is the management of postoperative pain very important to you?

$\square$ Yes $\square$ No $\square$ Don’t know What is the recommended route of administration $\square$ Intra-muscular; $\square$ Intravenous; $\square$ Oral of opioid analgesics on patients with severe pain? route $\square$ Subcutaneous $\square$ Intra-rectal

18 Does the patient have the right to expect complete relief of pain after treatment?

$\square$ Yes $\square$ No $\square$ Don't know 